\title{
Supply Chain Management in the Banking Industry: A Literature Review
}

\author{
Mohammad Ismail Majumder'1, Mohammad Mamun Habib² \\ ${ }^{1}$ Centre for Higher Studies, Bangladesh University of Professionals, Dhaka, Bangladesh \\ ${ }^{2}$ School of Business and Entrepreneurship, Independent University, Dhaka, Bangladesh \\ Email: majumder84@yahoo.com, mamunhabib@iub.edu.bd
}

How to cite this paper: Majumder, M. I., \& Habib, M. M. (2022). Supply Chain Management in the Banking Industry: A Literature Review. American Journal of Industrial and Business Management, 12, 10-20. https://doi.org/10.4236/ajibm.2022.121002

Received: December 4, 2021

Accepted: January 21, 2022

Published: January 24, 2022

Copyright $\odot 2022$ by author(s) and Scientific Research Publishing Inc. This work is licensed under the Creative Commons Attribution International License (CC BY 4.0).

http://creativecommons.org/licenses/by/4.0/ (c) (i) Open Access

\begin{abstract}
In this study, the authors demonstrate how Supply Chain Management (SCM) theory has evolved over time and how it applies in the banking industry which represents as one of the service industries. Various milestones of SCM evolution in the various industries have been identified by the authors to make it simpler to grasp. To begin with, the inception of logistics was first introduced in the 1950s. It was in the 1970s when logistics was first formed. The concept of supply chain management and the idea of coordinating the activities of enterprises within the chain were created in the 1980s. Logistics and supply chain management were finally separated in the 1990s, and supply chain management underwent a change. Throughout the early 2000s of global financial crisis, capital markets were extremely volatile, placing Supply Chain Finance in the spotlight, and eventually, the banking industry demanded more rigorous study from the standpoint of SCM. Though there is very little scholarly research in the banking industry, the authors intend to accomplish supply chain management model in the banking industry. The outcomes of this study will provide new avenues for research in the supply chain finance and banking industries. Therefore, this research unlocks the further frontiers for the prospective researchers in this area.
\end{abstract}

\section{Keywords}

Financial Supply Chain, Banking Industry, Supply Chain Management, SCM

\section{Introduction}

When it comes to Supply Chain Management (SCM), academics have tended to focus on how to generate more profit during the previous decade. Adding value, lowering costs, or shortening reaction time is some of the research aims for var- 
ious stakeholders engaged in the industrial supply chain. However, only a small number of research was conducted in non-profit organizations. In academia, there is an incredibly small number of research articles that are devoted to SCM in the banking industry.

To obtain competitive advantages in today's intensely competitive global economy, Supply Chain Management (SCM) has emerged as a critical component of business strategy (Simchi-Levi et al., 2008). Since the researchers and managers began to evolve into the studies and practices of SCM, there has been a significant amount of literature published on this subject of study. The majority of extant definitions of SCM are concerned with the movement of products and information from suppliers to consumers. As a result, SCM has historically been classified as a part of Operations Management. SCM is mostly used in industrial sectors, with only a small number of applications in service industries. Over the last few decades, the service industry has grown in importance as the driving force in the global economy. Moreover, in tandem with the rapid expansion of the service economy, the labor force changed, with a majority of workers transitioning from the manufacturing sector to the service sector, which is consistent with Clark's assumption, which was stated sixty years ago (Lin et al., 2010).

Furthermore, industrial corporations, such as General Motors and IBM, are generating more and more incomes from their service divisions. When it comes to typical manufacturing companies, the majority of their added value is created by their service constituents (Lin et al., 2010).

Supply chains are widely recognized as the integration of material, information, and financial exchanges between and across businesses. In order to better understand supply chain management in relation to material flow and process flows, decades of research have been conducted. The research agenda is constantly expanding. The management of financial flows from a supply chain perspective and in combination with other flows is called Supply Chain Finance (SCF), but this topic has gotten little attention (Caniato et al., 2019).

The literature on financial and banking supply chains has been sparse until recently, despite the vast quantity of academic work committed to Supply Chain Management (SCM), which mostly focuses on manufacturing supply networks. This provides us the motivation to close the gap. The following goals are revealed in this paper:

- To analyze comprehensive secondary data-based literature evaluations on SCM;

- To define the SCM and the evolution of SCM in a different area;

- To examine the latest SCM developments and how they affect in the banking industry.

\section{Literature Review}

In certain studies, the supply chain management idea is defined as a philosophy that examines a means of integrating activities inside and between companies in order to satisfy consumer demands in terms of the supply chain in order to meet 
client needs. In response to corporate organizations' realization that both consumers and suppliers may have a significant impact on supply processes, a partnership view on the supply chain was created, in which associations collaborate to achieve a higher shared goal. With an integrated mindset, the flow of a distribution channel may be managed between suppliers and end users. During the integration process, inventory management, organizational structures, sourcing, connected links, supply chain coordination, intra-enterprise communication, cost management, and production direction were all considered (Mukhamedjanova, 2020). Upstream and downstream connections connect the different companies in a supply chain, which are then involved in numerous processes and activities that generate value in the form of goods and services for the ultimate consumer (Habib, 2011). Figure 1 is a simplified illustration of a simple supply chain.

Suppliers, manufacturers, distributors, retailers, and end users make up the supply chain. A supply chain's primary goal is to meet customer demands while simultaneously earning a profit, thus customers are at the center of the chain's focus (Habib, 2011). In the beginning, Supply Chain Management (SCM) was linked to inventory management in a network of suppliers and customers. Over time, this idea evolved to encompass the management of all operations along the supply chain (Habib, 2011). By coordinating flows between and among supply chain stages, SCM aims to reduce total costs. According to this definition, Supply Chain Management (SCM) refers to the process of controlling product, financial flows, and information both upstream and downstream in the supply chain.

\subsection{Definitions of SCM}

Managing the movement of products and services along the supply chain is referred to as supply chain management. This covers things like storage, shelf life, analysis of the items procured and the goods sold, and transportation, among others. To build a net value for an organization, supply chain management aids in the planning and executing various supply chain activities of that organization. It also helps determine market trends related to demand and supply for any goods or services and synchronizes those trends in order to assess an organization's performance (Jaggi \& Kadam, 2016). Customer and other stakeholder values are added through Supply Chain Management (SCM), which is the integration of essential business activities from end-users via original suppliers (Desai \& Rai, 2016). In order to meet consumer expectations and enhance the supply chain's competitiveness, SCM integrates organizational units along the supply

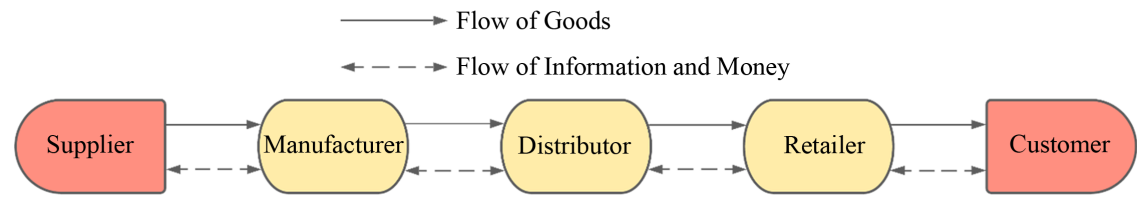

Figure 1. The basic supply chain (Habib, 2011). 
chain and coordinates commodities, information, and financial flows (Dias \& Ierapetritou, 2017).

Managing the supply chain adds value for customers and other stakeholders by distributing products, services, and information from end-users to original suppliers (Wibowo et al., 2017). There are many different types of companies and individuals engaged in transporting a product or service from one supplier to another. This is what is meant by the term "supply chain." Natural resources, raw materials, and component parts are transformed into a finished product and supplied to the ultimate consumer through the supply chain. An organization's network that is involved in the many processes and activities that generate value in the form of products and services that are supplied to the final customer through upstream and downstream links (Kain \& Verma, 2018).

The following summarizes the core supply chain philosophy (Mukhamedjanova, 2020):

1) To see the supply chain as complete and manage the whole flow of commodities from the supplier to the final client using a systems approach;

2) Internal operational and strategic convergence, with a focus on joint efforts to bring them all into harmony;

3) A focus on the customer to develop distinct and customized sources of customer value, which leads to customer happiness.

\subsection{Evolution of SCM}

A timeline could be used to illustrate the specialization of the idea of supply chain management from a historical viewpoint. The author has broken the chronology into five major stages (Figure 2) in the development of SCM in order to make it easier to comprehend.

A study of the supply chain literature was carried out in order to learn about previous studies. Prior to the 1950s, logistics was mostly considered to be a military function. Specifically, it had something to do with the acquisition, upkeep, and transportation of military buildings, as well as military goods and people. Physical distribution and logistics began to be studied and practiced in the 1960s

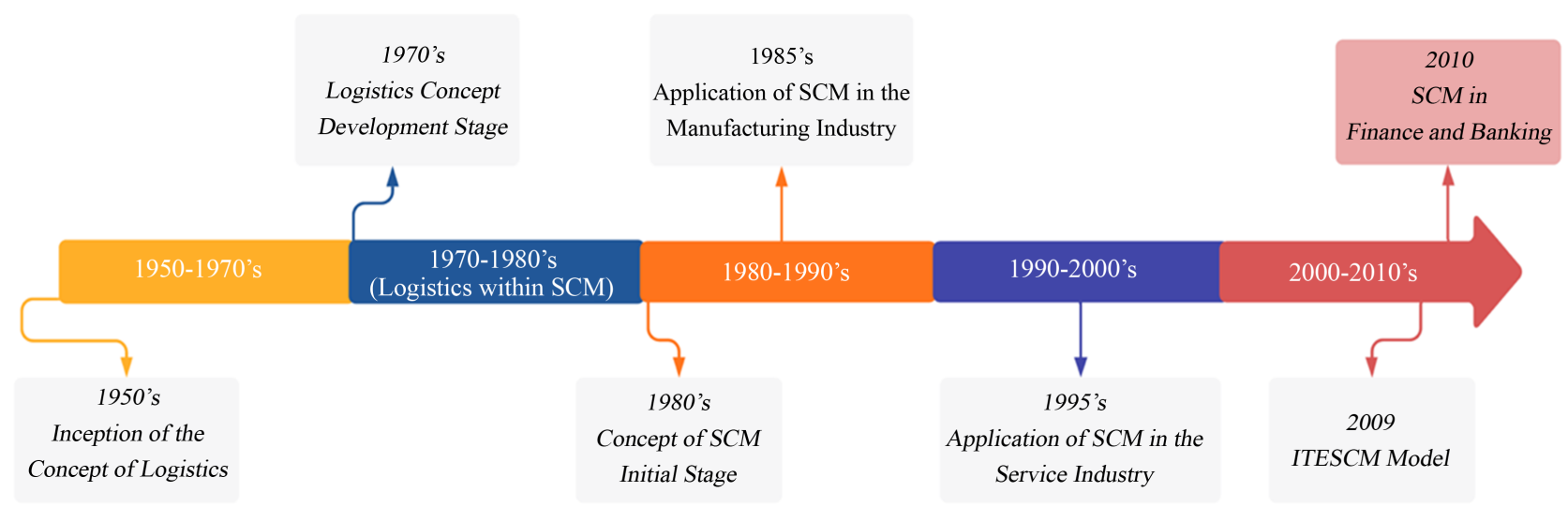

Figure 2. Evolutionary timeline of SCM. 
and 1970s, with the advent of the internet. Prior to 1950, the logistics industry has been referred to as the "dormant years" since logistics was not considered a strategic role.

Around the 1950s, a series of events happened that may be categorized as the first "transformation". When physical distribution management in industrial companies was recognized as a distinct organizational function, the importance of logistics rose significantly (Mukhamedjanova, 2020).

It became necessary in the 1980s to develop a new model of business management based on the notion of coordinating the flow of raw materials and completed products not only inside a single company but also across a network of companies linked by a technological chain. As of this point in its evolution, the content of the idea of "SCM" changed only little from the enlarged interpretation of integrated logistics, and the concept was virtually entirely influenced by it.

During the first part of the 1990s, the theory of supply chain management was separated from logistics, and independent studies of supply chain management as a science, as well as the sectors where its idea was used in actual operations, began to arise. There is a change and a split between logistics and supply chain management in terms of conceptual and semantic categories and individual words. It is necessary to organize the ideas and words used in logistics and supply chain management that are currently in use.

The distinction between integrated logistics and Supply Chain Management (SCM) is defined in the second half of the 1990s and the beginning of the 2000s, and the functions of control, coordination, and integration in the management of goods flow are assigned to the concept of "supply chain management" in the management of goods flow (Mukhamedjanova, 2020). The primary study topics are focused on the processes of integration and the establishment of strategic alliances, as well as guaranteeing the interconnection and management of product flows, as well as information coordination in order to ensure communications between the links in the distribution chain. Training courses in a new subject are formed by the general accumulation of theoretical and practical knowledge over a period of time.

There is even more in-depth research of the theory and practice of supply chain management, as well as their application to diverse markets, taking place in the second half of the twenty-first century. When it comes to developing partnerships between the focal firm and the rest of the supply chain, current supply chain management methods place a strong emphasis on in-house planning and resource efficiency.

Ferney used the SCM idea to the US National Health Service in 2006. This was the first SCM study in the service industry. Cigolini looked into the structure of supply chains for a variety of services, such as vehicle service, food service, computer service, typography, and so on. M. Habib published the first large-scale empirical research in 2009, which thoroughly examined the university's contributions and outcomes in the field of SCM in education. Educational supply chain, 
research supply chain and education management are the major components of the integrated supply chain management model in higher education (ITESCM) used in this study (Habib, 2010).

Digital supply chain management is a critical component of the "Digital Revolution", and it is becoming increasingly significant (Mukhamedjanova, 2020). When it comes to the transition to digital manufacturing and Internet commerce, we must consider logistics as a tool for managing value chains. We must determine where the changes that should take place in Supply Chain Management (SCM) should be focused in light of the transition to cyber production. Consider the changes already brought about by Information and Communication Technologies (ICTs), such as structural changes of companies, the boundaries of businesses of the economy, a set of key competencies, business models, and business strategies, and the importance of Digital SCM in these realities for integrating business processes into an interstitial of the digital economy of our country becomes clear. The efficiency and profitability with which businesses develop and deliver their products to clients are what distinguishes industry leaders from those that are falling behind. Companies that want to establish the actual worth of their business and the outcomes they achieve in a modern competitive global market must enhance the management of various elements of their operations, including inventories, costs, assets, and the launch of new goods. Also important to note is that none of this will be possible without a best-in-class digital supply chain that will completely revolutionize the world of modern logistics via the use of blockchain technology. In order to implement end-to-end data integration in their supply chains, which are organized as a network, even the largest businesses need the necessary capabilities, resources, and knowledge.

A supply chain network comprises several components, known as supply chain nodes, which are linked together through flow routes. According to the manufacturer, the inventory and goods and information that are sent through these flow pathways to various nodes of the supply chain have the ultimate objective of ensuring that customers' demands are met as efficiently as possible. According to the research findings on the evolution of logistics and supply chain management, these fields are constantly developing and reinventing their methodologies.

\subsection{Financial Supply Chain}

Material, information, and financial flows along supply networks have long been recognized as part of supply chain management as the structure, coordination, and integration of such flows (SCM). There has been a lot of attention paid to material and information flows in theory and practice, but little has been done to analyze and improve money flows (Caniato et al., 2019; Wuttke et al., 2016). Companies did not have to deal with liquidity issues or actively manage their supply chain's working capital before the global financial crisis of 2008-2009 since capital markets were liquid. As a result of the credit crunch during the financial crisis, many suppliers went bankrupt, putting the stability of the global supply chain 
in jeopardy (Hofmann \& Belin, 2011).

The importance of partnering with supply chain partners and financial institutions to manage money flows was beginning to be appreciated by companies everywhere. They set out on a mission to discover innovative methods for streamlining their financial distribution networks (Boer et al., 2015). Financial Supply Chain Management (FSCM) and supply chain finance, two newly founded academic fields, were being used to design such solutions (SCF). Because of this, SCF is frequently used in place of the more technically accurate word (Gelsomino et al., 2016). Through the use of financial institution or technology company-developed solutions, SCF hopes to improve inter-organizational money flows. Better cash-flow management is the ultimate goal of better matching financial flows across the supply chain with product and information movements (Gelsomino et al., 2016; Lamoureux \& Evans, 2011).

SCF provides a set of financial, technological, and managerial tools to help companies improve working capital management and free up cash trapped in supply chain processes and transactions (Caniato et al., 2016). Furthermore, SCF techniques may be used to resolve financial conflicts between suppliers and buyers, therefore strengthening their ties. Unlike buyers, who want to extend payment terms, suppliers prefer to get money for delivered products or services sooner. Stronger companies, such as big buyers, typically impose lengthier payment terms on weaker firms, such as smaller suppliers. Weaker businesses, on the other hand, are less likely to be able to amass financial resources to sustain larger levels of working capital, and they also face higher borrowing costs. In the long term, this leads to supply chain inefficiencies and dangers. By utilizing the buyer's high credit rating, SCF may create win-win scenarios for both buyers and suppliers, such as by offering financing options that allow buyers to defer payment.

On the other hand, suppliers get paid faster and at a lower rate. Other strategies try to improve the financial health of the supply chain by reducing both buyer and supplier working capital (Hofmann et al., 2018). Several SCF options have been discussed in the literature (Caniato et al., 2016). Initial SCF systems emphasized one-to-one relationships between large buyers and their suppliers, but more recently, multitier solutions have been developed, which incorporate companies from different levels of the supply chain and are driven by a focal firm.

\subsection{Supply Chain in Banking Industry}

Banks see the tightening of global credit as both a short-term problem and a longterm opportunity. In spite of the fact that cross-border opened account commerce between corporations' accounts for the great majority of cross-border opened account transactions, research implies that a significant portion will move to a bankassisted technique in the coming years. Companies and governments alike have expressed a desire for banks to facilitate more innovation in supply chains through 
their services (Casterman, 2010; Popa, 2013).

As a general rule, supply chain finance is considered to be the responsibility of a commercial bank's lending section. In the case of Buyers, working capital management is a service offered by relationship banks to their large company clients in the form of loans. At the same time, they provide their suppliers a variety of payment alternatives that are prompt (Popa, 2013).

SCF research has begun to shed light on various tools, and management strategies for efficiently managing and regulating money flows across supply chain participants. The relevance of SCF has not lessened since the crisis. Because of the development of conservative loan models and increasing regulatory capital requirements for banks, resulting in a scarcity of financing for many small and medium-sized businesses (Caniato et al., 2019; Lekkakos \& Serrano, 2016).

Large banks were the first to provide SCF services. In response to the increasing demand for SCF, new and novel financing methods emerged, and platform such as financial institutions and "fintech" later entered the market (Caniato et al., 2016). As a result, the SCF market is highly fragmented right now. It is not uncommon for companies to find themselves pushed to join and operate on many distinct SCF platforms run by banks and financial industry providers (Nienhuis et al., 2013). Prior to expanding into other areas, SCF's primary focus was on improving working capital and liquidity management. Currently, SCF solutions emphasize the importance of communication and effectiveness (Caniato et al., 2019).

\section{Research Methodology}

For the discussion of this research, we use secondary materials such as publications like books or journals or conference papers or digital libraries. EMERALD, PROQUEST, the IEEE, ACM, EBSCO, Science Direct, and JSTOR are some of the famous international journals where academic and practitioner SCM research papers have been published. An evolutionary timeline and forecasts for the future were derived from a survey of the literature. The author categorizes SCM in a variety of ways in both the industrial and service sectors.

\section{Discussion}

It is fairly evident that relatively few researchers performed SCM in the service sectors and finance \& banking respectively. Most of them practiced SCM in the industrial industry. It seems to be that SCM in the financial \& banking organizations requires more to be investigated in the future.

Bank-assisted transactions are expected to become more common in the future years, according to research. Corporations and governments in numerous nations want banks to innovate more through supply chain solutions. Relationship banks provide working capital management loans to its major corporate clients. Supply chain financing is often handled by a commercial bank's lending department. 
The supply chain management system's performance depends on the flawless coordination of all supply chain stakeholders to achieve the desired results. It is a startling truth that supply chain models are developed by researchers primarily for the purpose of enhancing company operations. In this illustration, the majority of financial-based supply chains were depicted as a supportive driver of the manufacturing-based supply chain process. Furthermore, supply chain bankingbased research is practically non-existent in the academic community.

However, despite the fact that this article is based solely on secondary data, which is a drawback of the paper, the findings of this study will open up new possibilities for substantial researchers in order to continue growth in the field of supply chain management and supply chain finance and banking industry.

\section{Conclusion}

This decade's research has focused on Supply Chain Management (SCM) across a wide range of industries. The definition of SCM remains a point of debate despite the growing popularity of SCM research and application. Scholars and practitioners have attempted to accurately describe SCM in numerous ways, with varying degrees of success. Because of this, SCM has gained traction as a triedand-true management method for long-term profitability and growth in a variety of industries. By focusing on all aspects of the supply chain management process, this may be done to deliver the correct amount, quality, and scheduling of goods and services to the right place at the right time.

Specifically, supply chain management, which has become one of the most prominent ideas in the previous 30 years, is examined in this study. The progression of the development of this notion was taken into consideration, with five major stages identified. The inception stage refers to the notion of logistics that was first introduced in the 1950s. In the 1980s, the notion of supply chain management was developed, as well as the idea of coordinating firms' operations within the chain. In the 1990s, the concept of focusing on end-customer needs and other forms of competition between chains as well as between individual firms was introduced, along with the separation of logistics from supply chain management and the reorganization of supply chain management as a whole, all of which were pioneered.

Several service industry domains are examined from a chronological viewpoint in this article. The researcher used secondary data such as digital libraries, Internet databases, journals, conference papers, and so on, to study SCM research articles from various angles. SCM has evolved across a variety of industries, including manufacturing and service, as well as its potential future applications. However, the study is restricted since it is exploratory; more research is needed to quantify the impact. Given the nature of this exploratory research project and the enormous amount of qualitative data that needed to be collected, this was deemed suitable. However, there is an obvious need for further empirical research and quantitative analysis in this sector, which the authors are also interested in exploring. 
The authors also dive deep into the development of the financial supply chain. This paper also discovers that there is a little research obtainable regarding the banking supply chain and desire to continue to investigate financial supply chain in the banking sector.

\section{Conflicts of Interest}

The authors declare no conflicts of interest regarding the publication of this paper.

\section{References}

Boer, R. D., Steeman, M., \& Bergen, M. V. (2015). Supply Chain Finance, Its Practical Relevance and Strategic Value. Supply Chain Finance Community.

Caniato, F., Gelsomino, L. M., Perego, A., \& Ronchi, S. (2016). Does Finance Solve the Supply Chain Financing Problem? Supply Chain Management: An International Journal, 21, 534549. https://doi.org/10.1108/scm-11-2015-0436

Caniato, F., Henke, M., \& Zsidisin, G. A. (2019). Supply Chain Finance: Historical Foundations, Current Research, Future Developments. Journal of Purchasing and Supply Management, 25, 99-104. https://doi.org/10.1016/j.pursup.2019.02.002

Casterman, A. (2010). Collaborative Supply Chain Finance. Dialogue Q4.

Desai, A., \& Rai, S. (2016). Knowledge Management for Downstream Supply Chain Management of Indian Public Sector Oil Companies. Procedia Computer Science, 79, 1021-1028. https://doi.org/10.1016/j.procs.2016.03.129

Dias, L. S., \& Ierapetritou, M. G. (2017). From Process Control to Supply Chain Management: An Overview of Integrated Decision Making Strategies. Computers \& Chemical Engineering, 106, 826-835. https://doi.org/10.1016/j.compchemeng.2017.02.006

Gelsomino, L. M., Mangiaracina, R., Perego, A., \& Tumino, A. (2016). Supply Chain Finance: A Literature Review. International Journal of Physical Distribution \& Logistics Management, 46. https://doi.org/10.1108/ijpdlm-08-2014-0173

Habib, M. (2010). An Empirical Research of ITESCM (Integrated Tertiary Educational Supply Chain Management) Model. In M. Habib (Ed.), Management and Services (pp. 1-24). IntechOpen. https://doi.org/10.5772/9950

Habib, M. (2011). Supply Chain Management (SCM): Theory and Evolution. In M. Habib (Ed.), Supply Chain Management-Applications and Simulations (pp. 1-14). IntechOpen. https://doi.org/10.5772/24573

Hofmann, E., \& Belin, O. (2011). Supply Chain Finance Solutions. Springer. https://doi.org/10.1007/978-3-642-17566-4

Hofmann, E., Heines, R., \& Omran, Y. (2018) Foundational Premises and Value Drivers of Blockchain-Driven Supply Chains: The Trade Finance Experience. In W. Tate, L. Bals, \& L. Ellram (Eds.), Supply Chain Finance: Risk Management, Resilience and Supplier Management (pp. 225-255). Kogan Page.

Jaggi, H. S., \& Kadam, S. S. (2016). Integration of Spark Framework in Supply Chain Management. Procedia Computer Science, 79, 1013-1020.

https://doi.org/10.1016/j.procs.2016.03.128

Kain, R., \& Verma, A. (2018). Logistics Management in Supply Chain-An Overview. Materials Today: Proceedings, 5, 3811-3816. https://doi.org/10.1016/j.matpr.2017.11.634

Lamoureux, J. F., \& Evans, T. A. (2011). Supply Chain Finance: A New Means to Support 
the Competitiveness and Resilience of Global Value Chains. SSRN Electronic Journal, 289-311. https://doi.org/10.2139/ssrn.2179944

Lekkakos, S. D., \& Serrano, A. (2016). Supply Chain Finance for Small and Medium Sized Enterprises: The Case of Reverse Factoring. International Journal of Physical Distribution \& Logistics Management, 46, 1-34. https://doi.org/10.1108/ijpdlm-07-2014-0165

Lin, Y., Shi, Y. J., \& Zhou, L. (2010). Service Supply Chain: Nature, Evolution, and Operational Implications. In G. Q. Huang, K. L. Mak, \& P. G. Maropoulos (Eds.), Advances in Intelligent and Soft Computing (pp. 1189-1204). Springer. https://doi.org/10.1007/978-3-642-10430-5 91

Mukhamedjanova, K. A. (2020). Concept of Supply Chain Management. Journal of Critical Reviews, 7, 759-766.

Nienhuis, J. J., Cortet, M., \& Lycklama, D. (2013). Real-Time Financing: Extending e-Invoicing to Real-Time SME Financing. Journal of Payments Strategy \& Systems, 7, 232-245.

Popa, V. (2013). The Financial Supply Chain Management: A New Solution for Supply Chain Resilience. Amfiteatru Economic Journal, 15, 140-153.

Simchi-Levi, D., Kaminsky, P., \& Simchi-Levi, E. (2008). Designing and Managing the Supply Chain: Concepts, Strategies, and Case Studies. McGraw-Hill/Irwin.

Wibowo, M. A., Sholeh, M. N. E., \& Adji, H. S. (2017). Supply Chain Management Strategy for Recycled Materials to Support Sustainable Construction. Procedia Engineering, 171, 185-190. https://doi.org/10.1016/j.proeng.2017.01.325

Wuttke, D. A., Blome, C., Heese, H. S., \& Protopappa-Sieke, M. (2016). Supply Chain Finance: Optimal Introduction and Adoption Decisions. International Journal of Production Economics, 178, 72-81. https://doi.org/10.1016/j.ijpe.2016.05.003 